\title{
A Fruit Recognition Technique using Multiple Features and Artificial Neural Network
}

\author{
Saswati Naskar \\ Assistant Professor \\ Dept. of CSE, GKCEM \\ Baruipur, 24 Pgs(S), WB, India
}

\author{
Tanmay Bhattacharya, Ph.D \\ Associate Professor \\ Dept. of IT, Techno India \\ Salt Lake, WB, India
}

\begin{abstract}
Feature based Fruit recognition technique that has been proposed several times in past revealed in maximum research works either the color and shape or shape and texture or texture and color features. Different fruit images may have same color or identical shape or similar type texture but all three features are rarely identical at the same time for two different types of fruit. So the classification of fruit considering the three features at the same time increases the efficiency and accuracy of the algorithm. The proposed method represents fruit recognition expanding multiple feature based analysis that includes texture, color and shape. To recognize the texture of a fruit the Log Gabor filter has been used, mean hue has been calculated for color and shape has been analyzed by counting perimeter and area pixel. In the study of fruit recognition texture analysis using Log Gabor has been rarely used. The Projected fruit recognition technique is used to extract the above mention three features and Artificial Neural Network is used for classification. The system has achieved more than $90 \%$ accuracy using successful implementation of the proposed algorithm.
\end{abstract}

\section{General Terms}

Machine Learning, Pattern Recognition.

\section{Keywords}

Fruit recognition, Log Gabor, Artificial Neural Network.

\section{INTRODUCTION}

Sometimes image expresses a lot of information than a document can. A lot of computer applications are also introduced to extract this information. Content Based Visual Information Retrieval (CBVIR) [1] which is also known as Query By Image Content (QBIC) is one of the applications of computer vision techniques to the image retrieval problem. Since information retrieval from an image had been introduced many years ago there is a wide range of techniques in this area. But CBVIR consist of four basic steps.

1. Pre-Processing.

2. Feature Extraction.

3. Feature Database creation, and then

4. Matching the feature of the query image to the database.

In this work fruit recognition [2,3] method is proposed where the three features (i.e., color, shape and texture) have been analyzed to recognize a fruit using CBVIR method.

Texture is one of the important features of an image. Not only fruits, it plays an important role in recognizing visual attribute that can easily differentiate images. Previously several texture feature extraction procedure have been developed like GLCM
[4] (Grey Level Co-occurrence Matrix) approach, SFTA algorithm [5] or DWT [6] (Discrete wavelet transform) method for image classification.

One of the texture features that had been established to extract through the image in SFTA algorithm for image classification is Hausdraff fractal dimension [7] of the different binary image. In this proposed work Hausdraff fractal dimension is used to find the texture feature of those images which has been filtered with different scales and different orientations of Log Gabor filter [8]. The texture feature of log Gabor filtered image had been processed for identification.

Color and shape are the other widely used visual features that can be used to identify fruit. HSV color model has been used to find the color feature and eclipse ratio $[9,10,11$, and 12] is used for defining the shape.

Extracted feature need some suitable method that can classify the trained image into different category. A build-in classifier can classify the image analyzing feature database. In this paper classification and testing is accomplished through artificial neural network training and simulation.

An approach has been projected to uniquely combine and use the three main characteristics to get a better fruit identification method through this work

\section{DIFFERENT FEATURES OF FRUIT}

\subsection{Texture}

In spatial domain Gabor filter has been found to be appropriate for the texture representation and discrimination. It is a Gaussian Kernel function modulated by a sinusoidal plane wave. The Gaussian kernel is defined in 2-D as [13]

$$
\mathrm{G} 2 \mathrm{D}(\mathrm{x}, \mathrm{y} ; \sigma)=\frac{1}{2 \Pi \sigma^{2}} \exp \left(-\frac{x^{2}+y^{2}}{2 \sigma^{2}}\right)
$$

The $\sigma$ satisfies the width of the Gaussian kernel. Gabor functions have Gaussian transfer functions when viewed on the linear frequency scale. Natural images are better coded by filters that have Gaussian transfer functions when viewed on the logarithmic frequency scale. On the linear frequency scale the log-Gabor function has a transfer function of the form [14]

$\log -$ Gabor $=\exp \left(\frac{-\log \left(\frac{\text { radius }}{f_{0}}\right) .^{\wedge} 2}{2 *(\log \text { sigmaOnf })^{\wedge} 2}\right)$ 
Where radius is a matrix that contain normalized radius values ranging from 0 at the center to 0.5 at the boundary, $f_{0}$ is the Centre frequency of filter and sigmaOnf signifies Ratio of the standard deviation of the Gaussian describing the log Gabor filter's transfer function in the frequency domain to the filter center frequency. Texture image are created by convolving the image with log Gabor filter.

Convolution is done by FFT. EO $\{\mathrm{s}, \mathrm{o}\}$ stores the convolution result for scale $\mathrm{s}$ and orientation $\mathrm{o}$.

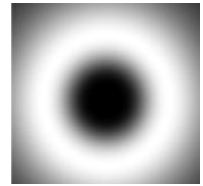

a) Frequency.

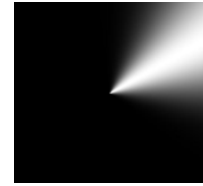

b) Orientation.

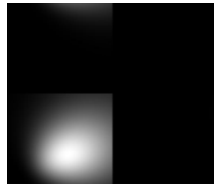

c) Combined Filter
Figure 1 Construction of log Gabor Filter.

a) Component Based on frequency.

b) Component Based on Orientation.

c) Final Filter combined by the two components.

The two dimensional $\log$ Gabor filter consist of two components: Frequency component (Fig 1.a) and component based on orientation (Figure 1.b). Final filter component is created by combining these two components (Figure 1. c).

In this practical application filter has been used in different scale and different orientation. Filtered image encompasses some self-repeating design and highlights the texture feature. Fractal dimension is a measure the complex property of those objects having a self-repeating configuration or it can clarify the texture property of any image. Hausdroff method finds the fractal dimension of textured Log-Gabor (Filtered) image.

\subsection{Color}

In case of visual feature another most important feature is color. Color that is explored by human beings enclosed with three color stimuli: Red, Green and Blue. This color model is specified as RGB color model. These three colors are the primary color component of an image as monitoring these three individual color component can modify the color outcome of an image.

The depiction of HSV color space can be derived from RGB color image. HSV is another color space consists of three components: Hue, Saturation and value. The two color models are shown in Figure 2.

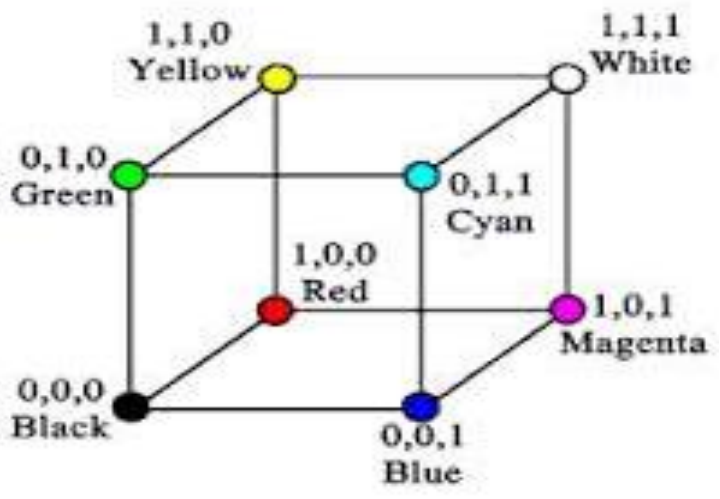

a)

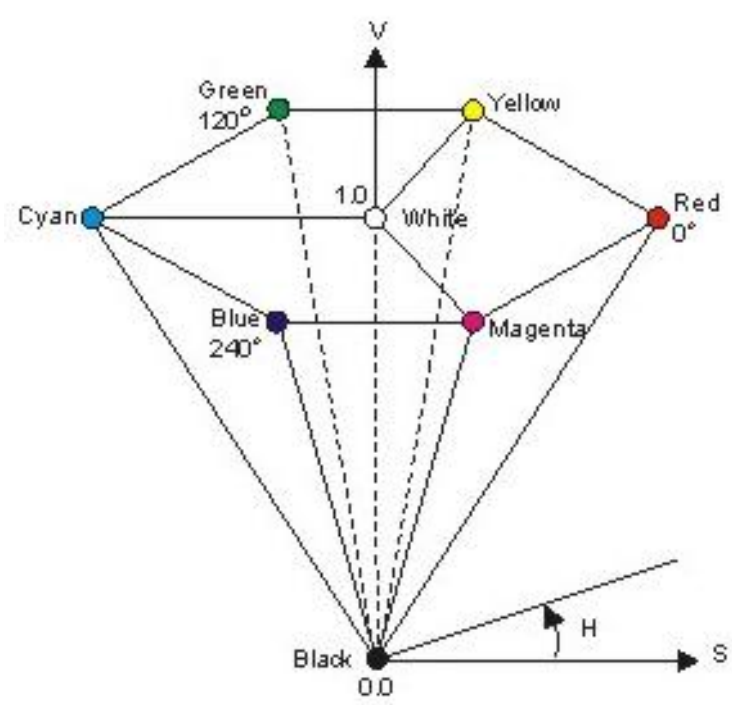

b)

Figure 2 a) RGB and b) HSV color space of image.

\subsection{Shape}

The third component that can be encountered as an attribute for fruit recognition is shape. The main motivation behind the shape analysis is that different fruits may have identical color or shape but possibilities of same value in both attributes (color and shape) are rare. The main stages that involves finding shape feature is boundary (Perimeter) and area pixel calculation [12] and calculating the shape as:

$$
\text { Shape }=4 \Pi *\left(\frac{\text { Area }}{\text { Perimeter }^{2}}\right)
$$

\section{PROPOSED ALGORITHM \& EXPLANATION}

The methodology or algorithm that involves in this scheme involves the following steps:

1. Fruit Feature Matrix has been declared and initialized to Zero.

2. Hausdroff fractal dimension has been calculated from the filtered image passing through the log Gabor filter. This feature is considered as Texture property of the image.

3. The fruit area has been identified and the mean hue of that area is calculated. This is considered as color Feature.

4. Perimeter and area have been calculated to find Shape attribute (Eq 3).

5. The values of the three attributes have been stored in the Feature Matrix.

6. Steps 2 to 6 have been repeated for all sample fruits.

7. The Fruit Class Matrix has been created.

8. The classification has been done through Matlab Neural Network Toolbox. 


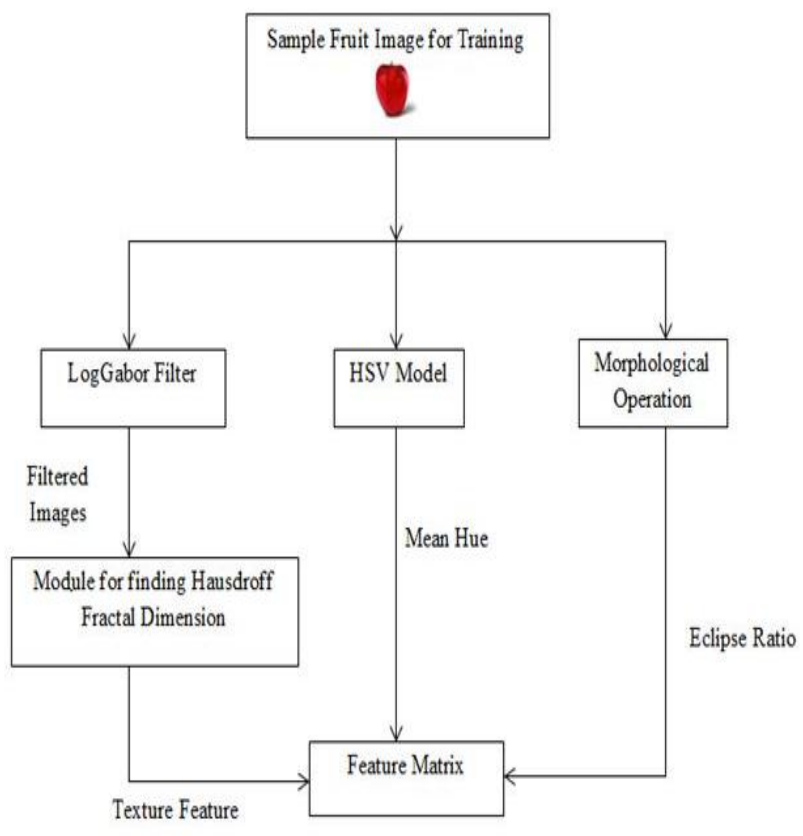

Figure 3 Flow Chart for feature extraction from sample fruit image

Figure 3 shows the flow chart of the procedure.

The subsequent Figure (Figure 4) shows the filtered image of sample data set.
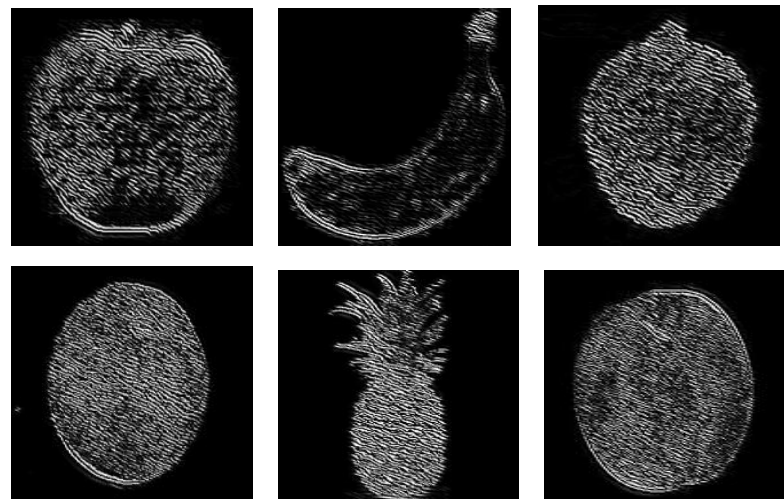

Figure 4 Different fruit image after filtered with Scale 2 and Orientation 3

The fractal Dimension is extracted from the filtered image and considered as the texture feature of that fruit.

Sometimes Fractal Dimension is not sufficient alone to distinguish between different fruit. To increase the proficiency of the method color is deliberated as the second feature to be explored. Color of a fruit is different from the other. So Feature that involves of color is also different from each other. In RGB color model as there are three color components, it is easier to find the HSV model so that color component (mean hue of the image area of particular fruit) could be extracted without difficulty. Following Figure 5 explicates the process.
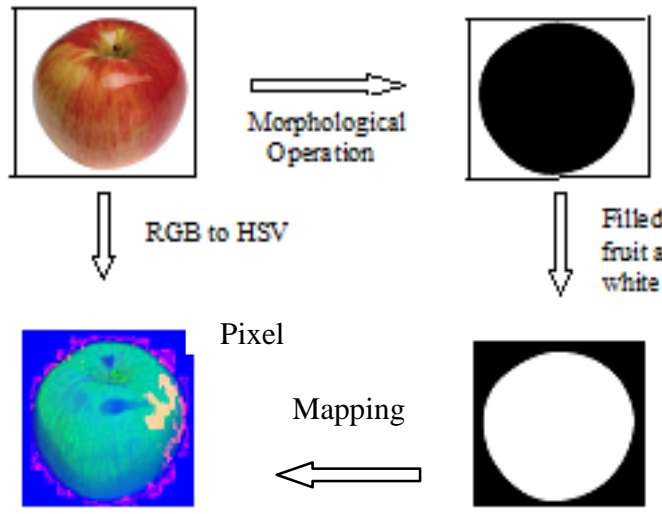

Pixel

Mapping
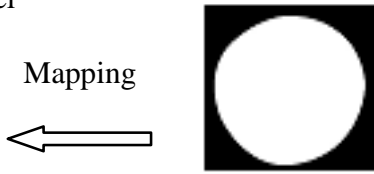

Mean Hue of the fruit region

Figure 5 Color feature Extraction.

Although accuracy at perfect level through machine intelligence is not always possible, it is more unreachable if all aspects are not examined through a detailed study. In fruit recognition technique shape is that another aspect that has been considered in this development along with texture and color to increase the robustness of the scheme.

In the process of calculating shape two parameters have been controlled: 1) Perimeter and Area. Both can be calculated through Morphological operation (Fig. 6). Perimeter is evaluated as the number of pixels on the boundary region and area is processed as number of pixels in the object (In case of this algorithm object is equivalent to fruit) region.

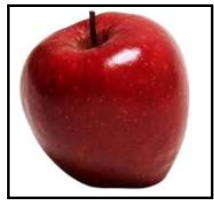

a)

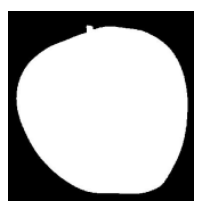

b)

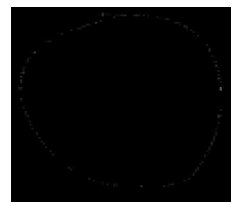

c)
Figure 6 a) Original Image b) Fruit Area

$$
\text { c) Boundary area }
$$

\section{EEPERIMENTAL RESULT}

Fruit identification in this work has been accomplished through the training of the neural network by assigning proper Feature matrix and defining the target class based on the input class (Fruit Type) of data set.

One hundred and fifty fruit images has been collected for fruit recognition. There are six classes (types) of fruit and each fruit has three features. That means a data set of size 3X150 has been used for training and the matrix used for classification is $6 \times 150$.

Neural network used for classification purpose is shown in Figure 7. 


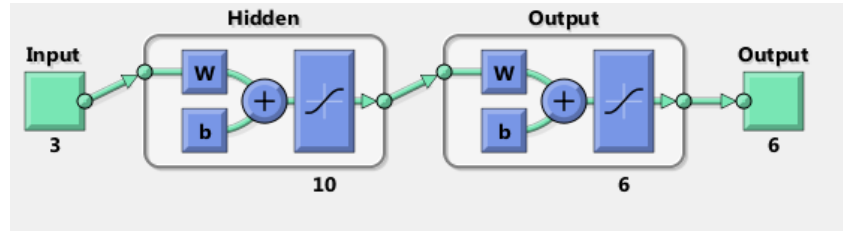

Figure 7 The Neural Network for Training.

The fruit data set of six different types of fruit and the classification matrices has been prepared and processed through the neural network for training.

After random division $70 \%$ of the fruit data samples has been assigned for training, $15 \%$ has been used for validation and remaining $15 \%$ has been applied for testing that provides an independent measure of network performance.

The following Table 1, 2 and 3 show the Maximum and minimum value for each class fruit for each feature.

Table 1 Minimum and Maximum round value of texture feature for each type of fruit.

\begin{tabular}{|c|c|c|c|}
\hline \multirow{2}{*}{$\begin{array}{c}\text { Class } \\
\text { Number }\end{array}$} & \multirow{2}{*}{ Fruit Class } & \multicolumn{2}{|c|}{ Texture Feature } \\
\cline { 3 - 4 } & & Min & Max \\
\hline 1 & Red Apple & 1.4760 & 1.6918 \\
\hline 2 & Banana & 1.2164 & 1.5182 \\
\hline 3 & Lychee & 1.3352 & 1.6788 \\
\hline 4 & Orange & 1.2882 & 1.6467 \\
\hline 5 & Pineapple & 1.4564 & 1.7105 \\
\hline 6 & Pomegranate & 1.4794 & 1.7792 \\
\hline
\end{tabular}

Texture value is the measure of mean fractal dimension of the filtered image for each scale and orientation. The images are required to be in gray scale for filtering.

Table 2 Minimum and Maximum round value of Mean Hue for each type of fruit.

\begin{tabular}{|c|c|c|c|}
\hline \multirow{2}{*}{$\begin{array}{c}\text { Class } \\
\text { Number }\end{array}$} & \multirow{2}{*}{ Fruit Class } & \multicolumn{2}{|c|}{ Shape Feature } \\
\cline { 3 - 4 } & & Min & Max \\
\hline 1 & Red Apple & 0.8753 & 1.1738 \\
\hline 2 & Banana & 0.2623 & 0.5928 \\
\hline 3 & Lychee & 0.1320 & 0.9525 \\
\hline 4 & Orange & 0.1106 & 1.5217 \\
\hline 5 & Pineapple & $6.7249 \mathrm{e}-04$ & 0.3709 \\
\hline 6 & Pomegranate & 0.0587 & 1.1458 \\
\hline
\end{tabular}

Color Feature is a measure of the mean hue calculated on the fruit area. This is achieved through Morphological operation followed by pixel comparison.

In this fruit recognition algorithm each of the three features that has been considered to characterize the class of a fruit are essential and necessary. It is examined that the status as well as the result of the algorithm would have greatly affected if one of the examined properties is absent. So optimization of the method is achieved through the detail study of all (Texture, Color \& Shape) aspect. The confusion matrix without Texture is shown in Figure 8 . The Figure $9 \& 10$ shows the Confusion matrix after training the same fruit data set without including shape and color feature accordingly.

The Figure 11 shows the confusion matrix after training.

Table 3 Minimum and Maximum round value of Shape feature for each type of fruit.

\begin{tabular}{|c|c|c|c|}
\hline \multirow{2}{*}{$\begin{array}{c}\text { Class } \\
\text { Number }\end{array}$} & \multirow{2}{*}{ Fruit Class } & \multicolumn{2}{|c|}{ Color Feature } \\
\cline { 3 - 4 } & & Min & Max \\
\hline 1 & Apple & 0.0626 & 0.9407 \\
\hline 2 & Banana & 0.1092 & 0.1698 \\
\hline 3 & Lychee & 0.0305 & 0.9468 \\
\hline 4 & Orange & 0.0687 & 0.4143 \\
\hline 5 & Pineapple & 0.1294 & 0.2383 \\
\hline 6 & Pomegranate & 0.0200 & 0.9325 \\
\hline
\end{tabular}

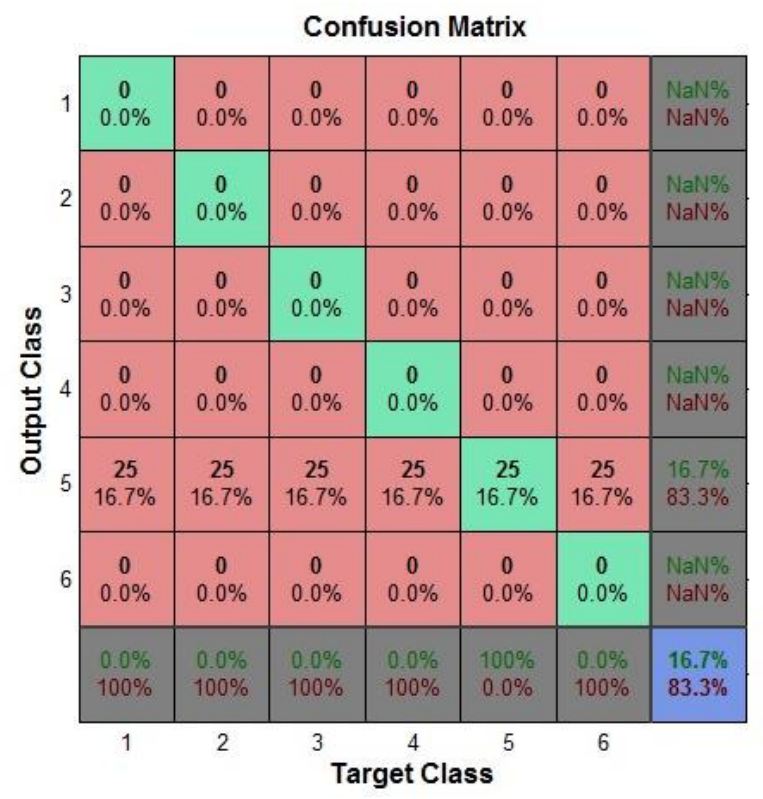

Figure 8 Confusion Matrix for Six types of fruit after training with considering color and shape feature.

As shown in Figure 8 the performance of the classifier significantly degraded during training the network without 
considering the texture feature. So texture analysis proved to be an indispensable unit of this scheme.

From the consequent Figure 9 and 10, the same realizations are experienced if among color or shape, any of the two features are not deliberated.

\section{Confusion Matrix}

\begin{tabular}{|c|c|c|c|c|c|c|c|}
\hline 1 & $\begin{array}{c}14 \\
9.3 \%\end{array}$ & $\begin{array}{c}0 \\
0.0 \%\end{array}$ & $\begin{array}{c}4 \\
2.7 \%\end{array}$ & $\begin{array}{c}1 \\
0.7 \%\end{array}$ & $\begin{array}{c}0 \\
0.0 \%\end{array}$ & $\stackrel{2}{1.3 \%}$ & $\begin{array}{l}66.7 \% \\
33.3 \%\end{array}$ \\
\hline 2 & $\begin{array}{c}2 \\
1.3 \%\end{array}$ & $\begin{array}{c}24 \\
16.0 \%\end{array}$ & $\begin{array}{c}0 \\
0.0 \%\end{array}$ & $\stackrel{2}{1.3 \%}$ & $\begin{array}{c}0 \\
0.0 \%\end{array}$ & $\begin{array}{c}0 \\
0.0 \%\end{array}$ & $\begin{array}{l}85.7 \% \\
14.3 \%\end{array}$ \\
\hline & $\begin{array}{c}7 \\
4.7 \%\end{array}$ & $\begin{array}{c}1 \\
0.7 \%\end{array}$ & $\begin{array}{c}\mathbf{1 6} \\
10.7 \%\end{array}$ & $\begin{array}{c}5 \\
3.3 \%\end{array}$ & $\stackrel{2}{1.3 \%}$ & $\begin{array}{c}4 \\
2.7 \%\end{array}$ & $\begin{array}{l}45.7 \% \\
54.3 \%\end{array}$ \\
\hline & $\begin{array}{c}0 \\
0.0 \%\end{array}$ & $\begin{array}{c}0 \\
0.0 \%\end{array}$ & $\begin{array}{c}3 \\
2.0 \%\end{array}$ & $\begin{array}{c}6 \\
4.0 \%\end{array}$ & $\begin{array}{c}0 \\
0.0 \%\end{array}$ & $\begin{array}{c}2 \\
1.3 \%\end{array}$ & $\begin{array}{l}54.5 \% \\
45.5 \%\end{array}$ \\
\hline & $\begin{array}{c}0 \\
0.0 \%\end{array}$ & $\begin{array}{c}0 \\
0.0 \%\end{array}$ & $\stackrel{2}{2} \%$ & $\begin{array}{c}0 \\
0.0 \%\end{array}$ & $\begin{array}{c}23 \\
15.3 \%\end{array}$ & $\begin{array}{c}1 \\
0.7 \%\end{array}$ & $\begin{array}{l}8.5 \% \\
11.5 \%\end{array}$ \\
\hline 6 & $\begin{array}{c}2 \\
1.3 \%\end{array}$ & $\begin{array}{c}0 \\
0.0 \%\end{array}$ & $\begin{array}{c}0 \\
0.0 \%\end{array}$ & $\begin{array}{c}11 \\
7.3 \%\end{array}$ & $\begin{array}{c}0 \\
0.0 \%\end{array}$ & $\begin{array}{c}16 \\
10.7 \%\end{array}$ & $\begin{array}{l}55.2 \% \\
44.8 \%\end{array}$ \\
\hline & $\begin{array}{l}56.0 \% \\
44.0 \%\end{array}$ & $\begin{array}{c}96.0 \% \\
4.0 \%\end{array}$ & $\begin{array}{l}64.0 \% \\
36.0 \%\end{array}$ & $\begin{array}{l}24.0 \% \\
76.0 \%\end{array}$ & $\begin{array}{c}92.0 \% \\
8.0 \%\end{array}$ & $\begin{array}{l}64.0 \% \\
36.0 \%\end{array}$ & $\begin{array}{l}66.0 \% \\
34.0 \%\end{array}$ \\
\hline & 1 & 2 & 3 & 4 & 5 & 6 & \\
\hline
\end{tabular}

Figure 9 Confusion Matrix for Six types of fruit after training with considering color and Texture feature.

\begin{tabular}{|c|c|c|c|c|c|c|c|}
\hline & \multicolumn{7}{|c|}{ Confusion Matrix } \\
\hline 1 & $\begin{array}{c}0 \\
0.0 \%\end{array}$ & $\begin{array}{c}0 \\
0.0 \%\end{array}$ & $\begin{array}{c}1 \\
0.7 \%\end{array}$ & $\begin{array}{c}0 \\
0.0 \%\end{array}$ & $\begin{array}{c}0 \\
0.0 \%\end{array}$ & $\begin{array}{c}0 \\
0.0 \%\end{array}$ & $\begin{array}{c}0.0 \% \\
100 \%\end{array}$ \\
\hline 2 & $\begin{array}{c}0 \\
0.0 \%\end{array}$ & $\begin{array}{c}23 \\
15.3 \%\end{array}$ & $\begin{array}{c}1 \\
0.7 \%\end{array}$ & $\begin{array}{c}1 \\
0.7 \%\end{array}$ & $\begin{array}{c}0 \\
0.0 \%\end{array}$ & $\begin{array}{c}1 \\
0.7 \%\end{array}$ & $\begin{array}{l}88.5 \% \\
11.5 \%\end{array}$ \\
\hline 3 & $\begin{array}{c}3 \\
2.0 \%\end{array}$ & $\begin{array}{c}0 \\
0.0 \%\end{array}$ & $\begin{array}{c}15 \\
10.0 \%\end{array}$ & $\begin{array}{c}0 \\
0.0 \%\end{array}$ & $\begin{array}{c}0 \\
0.0 \%\end{array}$ & $\begin{array}{c}4 \\
2.7 \%\end{array}$ & $\begin{array}{l}68.2 \% \\
31.8 \%\end{array}$ \\
\hline & $\begin{array}{c}21 \\
14.0 \%\end{array}$ & $\begin{array}{c}0 \\
0.0 \%\end{array}$ & $\begin{array}{c}0 \\
0.0 \%\end{array}$ & $\begin{array}{c}22 \\
14.7 \%\end{array}$ & $\begin{array}{c}0 \\
0.0 \%\end{array}$ & $\begin{array}{c}1 \\
0.7 \%\end{array}$ & $\begin{array}{l}50.0 \% \\
50.0 \%\end{array}$ \\
\hline 5 & $\begin{array}{c}0 \\
0.0 \%\end{array}$ & $\begin{array}{c}0 \\
0.0 \%\end{array}$ & $\begin{array}{c}1 \\
0.7 \%\end{array}$ & $\begin{array}{c}0 \\
0.0 \%\end{array}$ & $\begin{array}{c}25 \\
16.7 \%\end{array}$ & $\begin{array}{c}0 \\
0.0 \%\end{array}$ & $\begin{array}{c}96.2 \% \\
3.8 \%\end{array}$ \\
\hline 6 & $\begin{array}{c}1 \\
0.7 \%\end{array}$ & $\begin{array}{c}2 \\
1.3 \%\end{array}$ & $\begin{array}{c}7 \\
4.7 \%\end{array}$ & $\begin{array}{c}2 \\
1.3 \%\end{array}$ & $\begin{array}{c}0 \\
0.0 \%\end{array}$ & $\begin{array}{c}\mathbf{1 9} \\
12.7 \%\end{array}$ & $\begin{array}{l}61.3 \% \\
38.7 \%\end{array}$ \\
\hline & $\begin{array}{c}0.0 \% \\
100 \%\end{array}$ & $\begin{array}{c}92.0 \% \\
8.0 \%\end{array}$ & $\begin{array}{l}60.0 \% \\
40.0 \%\end{array}$ & $\begin{array}{l}88.0 \% \\
12.0 \%\end{array}$ & $\begin{array}{l}100 \% \\
0.0 \%\end{array}$ & $\begin{array}{l}76.0 \% \\
24.0 \%\end{array}$ & $\begin{array}{l}69.3 \% \\
30.7 \%\end{array}$ \\
\hline & 1 & 2 & 3 & 4 & 5 & 6 & \\
\hline & & & & & & & \\
\hline
\end{tabular}

Figure 10 Confusion Matrix for Six types of fruit after training with considering Texture and shape feature.

\begin{tabular}{|c|c|c|c|c|c|c|c|}
\hline \multicolumn{8}{|c|}{ Confusion Matrix } \\
\hline 1 & $\begin{array}{c}19 \\
12.7 \%\end{array}$ & $\begin{array}{c}0 \\
0.0 \%\end{array}$ & $\begin{array}{c}0 \\
0.0 \%\end{array}$ & $\begin{array}{c}0 \\
0.0 \%\end{array}$ & $\begin{array}{c}0 \\
0.0 \%\end{array}$ & $\begin{array}{c}1 \\
0.7 \%\end{array}$ & $\begin{array}{r}95.0 \% \\
5.0 \%\end{array}$ \\
\hline 2 & $\begin{array}{c}0 \\
0.0 \%\end{array}$ & $\begin{array}{c}25 \\
16.7 \%\end{array}$ & $\begin{array}{c}0 \\
0.0 \%\end{array}$ & $\begin{array}{c}0 \\
0.0 \%\end{array}$ & $\begin{array}{c}0 \\
0.0 \%\end{array}$ & $\begin{array}{c}0 \\
0.0 \%\end{array}$ & $\begin{array}{l}100 \% \\
0.0 \%\end{array}$ \\
\hline 3 & $\begin{array}{c}0 \\
0.0 \%\end{array}$ & $\begin{array}{c}0 \\
0.0 \%\end{array}$ & $\begin{array}{c}\mathbf{1 7} \\
11.3 \%\end{array}$ & $\begin{array}{c}1 \\
0.7 \%\end{array}$ & $\begin{array}{c}0 \\
0.0 \%\end{array}$ & $\begin{array}{c}4 \\
2.7 \%\end{array}$ & $\begin{array}{l}77.3 \% \\
22.7 \%\end{array}$ \\
\hline & $\begin{array}{c}5 \\
3.3 \%\end{array}$ & $\begin{array}{c}0 \\
0.0 \%\end{array}$ & $\begin{array}{c}1 \\
0.7 \%\end{array}$ & $\begin{array}{c}23 \\
15.3 \%\end{array}$ & $\begin{array}{c}0 \\
0.0 \%\end{array}$ & $\begin{array}{c}0 \\
0.0 \%\end{array}$ & $\begin{array}{l}79.3 \% \\
20.7 \%\end{array}$ \\
\hline 5 & $\begin{array}{c}0 \\
0.0 \%\end{array}$ & $\begin{array}{c}0 \\
0.0 \%\end{array}$ & $\begin{array}{c}2 \\
1.3 \%\end{array}$ & $\begin{array}{c}1 \\
0.7 \%\end{array}$ & $\begin{array}{c}25 \\
16.7 \%\end{array}$ & $\begin{array}{c}1 \\
0.7 \%\end{array}$ & $\begin{array}{l}86.2 \% \\
13.8 \%\end{array}$ \\
\hline 6 & $\begin{array}{c}1 \\
0.7 \%\end{array}$ & $\begin{array}{c}0 \\
0.0 \%\end{array}$ & $\begin{array}{c}5 \\
3.3 \%\end{array}$ & $\begin{array}{c}0 \\
0.0 \%\end{array}$ & $\begin{array}{c}0 \\
0.0 \%\end{array}$ & $\begin{array}{c}\mathbf{1 9} \\
12.7 \%\end{array}$ & $\begin{array}{l}76.0 \% \\
24.0 \%\end{array}$ \\
\hline & $\begin{array}{l}76.0 \% \\
24.0 \%\end{array}$ & $\begin{array}{c}100 \% \\
0.0 \%\end{array}$ & $\begin{array}{l}68.0 \% \\
32.0 \%\end{array}$ & $\begin{array}{c}92.0 \% \\
8.0 \%\end{array}$ & $\begin{array}{l}100 \% \\
0.0 \%\end{array}$ & $\begin{array}{l}76.0 \% \\
24.0 \%\end{array}$ & $\begin{array}{l}85.3 \% \\
14.7 \%\end{array}$ \\
\hline & 1 & 2 & 3 & 4 & 5 & 6 & \\
\hline
\end{tabular}

Figure 11 Confusion Matrix for Six types of fruit after training considering all (texture, shape, color) features.

A data set of forty fruits are taken for testing by the network. Table 4 shows the result after classification.

Table 4 Tested Results after Classification.

\begin{tabular}{|c|c|c|c|}
\hline \multirow{2}{*}{ Fruit. } & \multirow{2}{*}{$\begin{array}{c}\text { Total } \\
\text { Number }\end{array}$} & \multicolumn{2}{|c|}{ Identification. } \\
\hline & & Right & Wrong \\
\hline Orange. & 10 & 9 & 1 \\
\hline $\begin{array}{c}\text { Red } \\
\text { Apple. }\end{array}$ & 10 & 10 & 0 \\
\hline $\begin{array}{c}\text { Pomegra } \\
\text { nate. }\end{array}$ & 10 & 9 & 1 \\
\hline Pineapple & 10 & 10 & 0 \\
\hline
\end{tabular}

\section{CONCLUSION}

Other fruit recognition techniques that were introduced earlier, rarely considered the three characteristics to properly classify the fruit. From the experimental result it has been observed that extraction of color, texture and shape features for fruit recognition significantly improve the efficiency of the algorithm. Thus in this work an attempt has been taken to optimize the recognition technique accounting the above mentioned visible features. Texture property extracted from a Log Gabor filtered image is infrequently and hardly used for fruit recognition, which has been considered in this work. A randomly chosen data set of fruit is applied to the Artificial Neural Network classifier for testing. According to the result, most of the cases it has been accomplished without any confusion. This work can be enhanced through the inclusion 
of some new features so that more accuracy can be achieved. The main constraint of the work is single fruit image with white background has been considered for training as well as for testing. In the future work sincere attempt may be taken to overcome the constraint.

\section{REFERENCES}

[1] Ryszard S. Choras, "Image Feature Extraction Techniques and their applications for CBIR and Biometrices Systems", International Journal of Biology and Biomedical Engineering, Issue 1 vol. 1, 2007.

[2] L. Yang, J. Dickinson, Q. M. J. Wu, S. Lang, "A Fruit Recognition Method for Automatic Harvesting", http://ieeexplore.ieee.org/xpl/mostRecentIssue.jsp? punumber=4430702, 4-6 Dec. 2007, Pg. $152-157$.

[3] Hetal N. Patel, Dr. R. K. Jain, Dr. M. V. Joshi, "Fruit Detection using Improved Multiple Features based Algorithm", International Journal of computer Applications (0975-8887), Volume 13- No.2, January 2011.

[4] P. Mohanaiah, P. Sathyanarayana, L. GuruKumar, "Image Texture Feature Extraction Using GLCM Approach", International Journal of Scientific and Research Publications, Volume 3, Issue 5, May 20131 ISSN 2250-3153.

[5] Costa, A. F., G. E. Humpire-Mamani, A. J. M. Traina. 2012. "An Efficient Algorithm for Fractal Analysis of Textures." In SIBGRAPI 2012 (XXV Conference on Graphics, Patterns and Images), 39-46, Ouro Preto, Brazil.

[6] Kamarul Hawari Ghazali, Mohd Fais Mansor, Mohd. Marzuki Mustafa, Aini Hussain, "Feature Extraction Technique using Discrete Wavelet Transform for Image Classification", The $5^{\text {th }}$ Student Conference on Research and Development - SCOReD 2007 11-12 December 2007, Malaysia.
[7] Dierk Schleicher, "Hausdorff Dimension, Its Properties, and Its Surprises", THE MATHEMATICAL ASSOCIATION OF AMERICA [Monthly 114 June-July 2007]

[8] D. J. Field, "Relations Between the Statistics of Natural Images and the Response Properties of Cortical Cells", Journal of The Optical Society of America A, Vol 4, No 12, December 1987. pp 2379-2394

[9] S. Arivazhagan, R. Newlin Shebiah, S. Selva Nidhyanandhan, L. Ganesan, "Fruit Recognition using Color and Texture Features", Journal of Emerging Trends in Computing and Information Sciences, VOL. 1, NO. 2, Oct 2010

[10] E. Umbaugh, S., Computer Vision and Image Processing: A Practical Approach using CVIP tools. First ed. 1998: Prentice Hall Professional Technical Reference.

[11] Group, T.M.R. Image Processing Toolbox User's Guide. 2008 [cited 14 ${ }^{\text {th }}$ November 2008]; Available from: http://www.mathworks.com/products/image/description1 .html.

[12] Woo Chaw Seng, Seyed Hadi Mirisaee," A New Method for Fruits Recognition System", $\mathrm{http} / / /$ ieeexplore.ieee.org/ $\mathrm{xpl} /$ mostRecentIssue.jsp?punumber=5235860, 5-7 Aug. 2009, Pg. $130-134$.

[13] Michael Lindenbaum, Roman Sandler, "Gabor Filter Analysis for Texture Segmentation", Technion Computer Science Department - Technical Report CIS2005-05-2005.

[14] B.Sathya Bama, S.Mohana Valli, S.Raju, V.Abhai Kumar, "Content Based Leaf Image Retrieval (Cblir) Using Shape, Color And Texture Features", B. Sathya Bama et al./ Indian Journal of Computer Science and Engineering (IJCSE), Vol. 2 No. 2 Apr-May 2011. 